\title{
Treatment of severe diabetic hypoglycemia with glucagon: an underutilized therapeutic approach
}

This article was published in the following Dove Press journal:

Diabetes, Metabolic Syndrome and Obesity:Targets and Therapy

5 September 201I

Number of times this article has been viewed

\author{
Nitil Kedia \\ Colney Medical Centre, London \\ Colney, Herts, UK
}

Correspondence: Nitil Kedia

Colney Medical Centre,

45-47 Kings Road, London Colney,

Herts, AL2 IES UK

Tel +441727822138

Fax +44 1727822130

Email nitil.kedia@nhs.net

\begin{abstract}
Tight glycemic control is important in reducing and delaying vascular complications in type 1 and 2 diabetes patients; however, the benefits achieved through strict metabolic control are counterbalanced by an increased risk of hypoglycemia. Glucagon is an effective therapy for treating severe hypoglycemia. Available as an emergency kit, glucagon is an essential tool for rapid response, but remains underappreciated and underused. This article reviews the role of glucagon in treating severe hypoglycemia and discusses the need for better education on glucagon for people with diabetes and their caregivers in order to alleviate fears of hypoglycemia and of administering glucagon in the event of an emergency.
\end{abstract}

Keywords: severe hypoglycemia, glucagon, type 1 diabetes, type 2 diabetes

\section{Introduction}

It is well documented that tight glycemic control improves vascular complications in people with type 1 and type 2 diabetes. Seminal studies, including the Diabetes Control and Complications Trial (DCCT) and the United Kingdom Prospective Diabetes Study (UKPDS), conclusively support the implementation of strict glycemic thresholds to delay progression of diabetes complications. ${ }^{1-6}$ However, the benefits conferred by strict metabolic control are counterbalanced by the increased risk of hypoglycemia that is an inevitable side effect of intensive insulin therapy. ${ }^{6}$

Hypoglycemia is associated with significant morbidity: physical (such as palpitations, sweating, and neurological impairments) as well as psychological (such as mood disturbance and generalized worry and fear of hypoglycemia) $;^{7-9}$ reductions in quality of life; and risk of death, ${ }^{9}$ with $2 \%-6 \%$ of all deaths in people with type 1 diabetes being attributed to hypoglycemia. ${ }^{10,11}$ Similarly, in patients with type 2 diabetes receiving sulfonylurea monotherapy, severe hypoglycemia has been associated with an overall mortality rate of $9 \% .{ }^{12}$ In the Action to Control Cardiovascular Risk in Diabetes (ACCORD) study, the use of intensive therapy for 3.7 years to target a glycated hemoglobin (HbA1c) level below 6\% reduced 5-year nonfatal myocardial infarctions but increased 5-year mortality, leading the author to conclude that this treatment strategy should not be recommended for high-risk patients with advanced type 2 diabetes. ${ }^{13}$ The fear of future hypoglycemia events is often the underlying source of inappropriate management of diabetes and suboptimal glycemic control. ${ }^{14}$ Self-management and regular monitoring of blood glucose levels are invaluable tools that aid the recognition of the signs and symptoms of hypoglycemia, therefore reducing the risk of hypoglycemia. While the implementation of continuous glucose 
monitoring systems holds promise in children and adults for maintaining glycemic thresholds without a concurrent risk of hypoglycemia, ${ }^{15,16}$ studies have reported discrepancies between readings of continuous glucose monitors and blood glucose levels. ${ }^{17,18}$ Moreover, analysis of continuous glucose data is challenging and no method has yet been devised to overcome the issues associated with measuring such data. ${ }^{18}$ Therefore, there remains a need for precautionary measures to manage severe hypoglycemia events when they do occur.

The purpose of this review paper is to discuss causes and management of hypoglycemia with an emphasis on glucagon, which is the only first-line treatment for severe hypoglycemia that can be administered in a nonmedical environment. Reasons for the underuse of glucagon are also discussed. ${ }^{19}$

Medline searches were conducted using combinations of the search terms diabetes, hypoglycemia, glucagon, GlucGen ${ }^{\circledR}$ Hypokit $^{\circledR}$ and The Glucagon Emergency Kit and articles were selected for relevance to the review paper. The reference sections of the selected publications were also searched for further relevant publications. Manufacturer/ product websites were viewed and Google searches conducted using the above search terms to attain further information on glucagon kits.

\section{Defining hypoglycemia}

There is currently a lack of consensus regarding the threshold blood glucose levels that classify different stages of hypoglycemia. Existing thresholds for defining hypoglycemia are based on observations from clinical trial settings and may not be applicable to everyday practice. ${ }^{2}$ Variations in blood glucose threshold levels across different individuals also contribute to the failure to reach agreement on a universal clinical definition of hypoglycemia. For example, symptoms of hypoglycemia are likely to occur at higher levels of blood glucose in people who are poor at controlling their blood glucose levels than in people who tightly control their diabetes. ${ }^{9,20}$ Moreover, younger patients and those who have had diabetes for a short time are likely to detect an episode of hypoglycemia at higher plasma glucose levels. ${ }^{9,20}$ Notwithstanding individual considerations, there are general guidelines that define an episode of hypoglycemia as being mild (minor)-to-moderate or severe, dependent upon the patient's ability to treat himself/herself.

Mild (minor)-to-moderate hypoglycemia is defined as: a hypoglycemia event that can be self-treated irrespective of symptom severity, or an asymptomatic blood glucose measurement of $\leq 3.9 \mathrm{mmol} / \mathrm{L} .{ }^{2,8,21}$ Severe hypoglycemia is defined as: a hypoglycemia event that requires external (third-party) assistance. ${ }^{21}$ Notably, younger children will almost always need to be treated by a parent or caregiver when experiencing hypoglycemia; they may also have difficulty explaining their symptoms verbally so it is necessary for parents or caregivers to monitor behavior closely in order to detect possible hypoglycemia. According to the International Society of Pediatric and Adolescent Diabetes (ISPAD) guidelines of 2006-2007, severe hypoglycemia is when the child has "altered mental status and cannot assist in their care, is semiconscious or unconscious, or in coma with or without convulsions and may require parenteral therapy (glucagon or intravenous [IV] glucose)". ${ }^{22}$

Reported estimates suggest a high incidence of hypoglycemia among adults and children with type 1 diabetes, with two symptomatic hypoglycemic episodes per week and episodes of severe hypoglycemia approximating to 11.5 per 100 patient-years or 0.21 to 1.6 per patient per year (Figure 1). ${ }^{9,21,23-25}$ Hypoglycemia is less common, but still important, in type 2 diabetes; the incidence is approximately $10 \%-20 \%$ of the observed rate in people with type 1 diabetes. ${ }^{21,23-25}$ However, comparable with estimates for type 1 diabetes, severe hypoglycemic episodes in patients with type 2 diabetes treated with insulin have been reported to be as high as 11.8 per 100 patient-years. $^{23}$

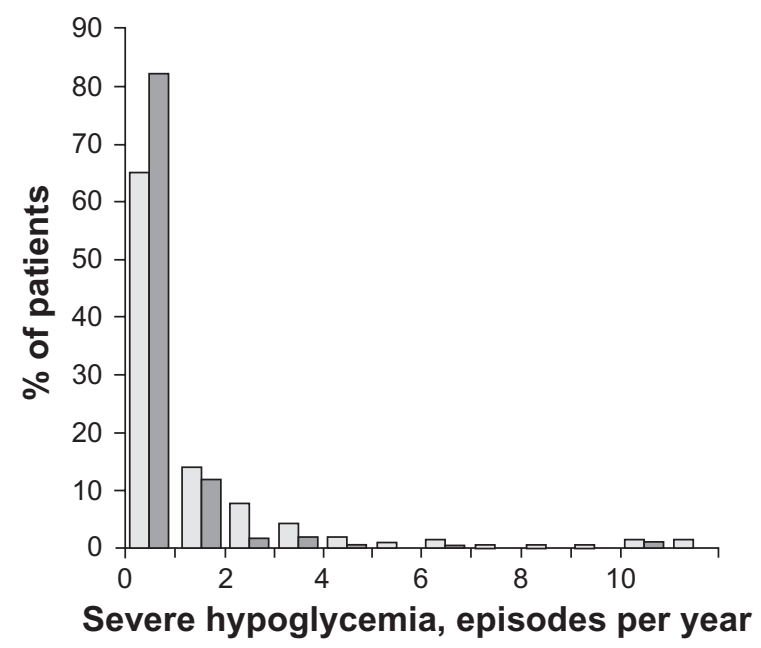

Figure I Distribution of self-reported number of episodes of severe hypoglycemia during the preceding year in 1049 unselected subjects with type I diabetes (light bars) and 209 patients with type I diabetes selected by criteria to mimic the characteristics of the DCCT cohort (dark bars).

Reprinted from Diabetes Metab Res Rev, 20, U Pedersen-Bjergaard, S Pramming, SR Heller, et al, Severe hypoglycaemia in 1076 adult patients with type I diabetes: influence of risk markers and selection, 479-486, copyright (2004), with permission from John Wiley \& Sons. 


\section{What are the causes and symptoms of hypoglycemia?}

\section{Causes}

The most frequently attributed cause of hypoglycemia is treatment with insulin or sulfonylureas (iatrogenic hypoglycemia), but additional underlying causes of nondiabetic hypoglycemia include pancreatic or nonislet cell tumors, autoimmune conditions (for example, autoimmune insulin syndrome), organ failure, endocrine disease, inborn errors of metabolism, dietary toxins, and miscellaneous conditions (such as sepsis, starvation, severe excessive exercise). ${ }^{26}$ Table 1 lists several causes of hypoglycemia for people with diabetes. ${ }^{27}$ Among these possible causes, a recent study investigating the management of severe hypoglycemia in type 1 or insulin-treated type 2 diabetes in Germany, Spain and the UK, found that insufficient food consumption was the most common cause ( $43 \%$ or $47 \%$ of type 1 or 2 patients with diabetes in all countries, respectively; Figure 2) followed by physical exercise/over-exertion $(24 \%$ or $23 \%)$, and insulin dose miscalculation $(24 \%$ of type 1 diabetes patients) or stressful situations (17\% of type 2 diabetes patients). ${ }^{28}$ The frequencies of these major causes of hypoglycemia in the type 1 and 2 diabetes patient groups were similar between countries. However, a notably greater proportion of German patients with type 1 diabetes (and, to a lesser extent, patients with type 2 diabetes from Germany) reported stressful situations, oscillating blood glucose levels, and impaired hypoglycemia awareness as a cause of hypoglycemia than patients in Spain and the UK (Figure 2).

Table I Causes of hypoglycemia

\begin{tabular}{ll}
\hline Cause & Example \\
\hline Incorrect insulin administration & $\begin{array}{l}\text { Insulin taken in excess or at the } \\
\text { wrong time relative to food intake } \\
\text { and/or physical activity; incorrect } \\
\text { type of insulin taken } \\
\text { Delayed or missed meals or } \\
\text { overnight fast } \\
\text { Excess alcohol consumption } \\
\begin{array}{l}\text { Insufficient exogenous } \\
\text { carbohydrate }\end{array} \\
\begin{array}{l}\text { Decreased endogenous } \\
\text { glucose production }\end{array} \\
\begin{array}{l}\text { Increased utilization of } \\
\text { carbohydrate/depletion of } \\
\text { hepatic glycogen stores } \\
\text { Increased insulin sensitivity }\end{array} \\
\begin{array}{l}\text { Exercise or weight loss } \\
\text { Delayed gastric emptying }\end{array} \\
\begin{array}{l}\text { Decreased insulin clearance } \\
\text { weight loss } \\
\text { Conditions such as gastroparesis }\end{array} \\
\text { Conditions such as progressive } \\
\text { renal failure }\end{array}$ \\
\hline
\end{tabular}

\section{Risks}

A number of factors increase the risk of severe hypoglycemia in insulin-treated people with diabetes. Impaired awareness of hypoglycemia is a major risk factor, those with impaired awareness being up to nine times more likely to have a severe hypoglycemic episode than those with normal awareness. ${ }^{29-31}$ Approximately $25 \%$ of patients with type 1 diabetes have impaired hypoglycemia awareness, with a lower incidence in those with type 2 diabetes. ${ }^{31-33}$ Such unawareness means there is an inability to detect the onset of hypoglycemia, and consequently, the individual is less likely to start corrective action sooner and more likely to go on to suffer severe episodes. Young age is also a risk factor for severe hypoglycemia due to lower awareness of the signs and symptoms, ${ }^{8,34}$ and the elderly also have less awareness of the signs and symptoms of hypoglycemia as a result of the aging process. ${ }^{23}$ Avoidance of severe hypoglycemia is particularly challenging in children and adolescents with diabetes since parents usually bear the responsibility for decisions on food intake, adjustment of insulin dosage, and appropriate management of exercise. ${ }^{8}$ A long duration of the disease ${ }^{2,23,35}$ and previous experiences of severe hypoglycemia ${ }^{2,24}$ are additional risk factors for severe hypoglycemia.

\section{Symptoms}

Signs and symptoms of the onset of hypoglycemia are typified by autonomic symptoms such as tremor, hunger, sweating and palpitations (acting as early warnings to the patient of an impending episode) and nonspecific symptoms such as headache and nausea (Figure 3). ${ }^{36-38}$ Symptoms of hypoglycemia may become progressively less intense over time or even diminish altogether, resulting in impaired awareness of hypoglycemia in a significant proportion of people (25\%). ${ }^{39}$ Of the 201 patients whose awareness of hypoglycemia was questioned in a recent survey, $68 \%$ had normal awareness. Those patients needing health care treatment for severe hypoglycemia in this study often had impaired awareness and developed hypoglycemic coma more frequently. ${ }^{28}$ Children may be more vulnerable to hypoglycemia than adults, with observations of frequent failures among children and their parents to accurately recognize the early signs and symptoms of hypoglycemia. ${ }^{40}$

\section{Pathophysiology}

In diabetes, hypoglycemia arises from the combination of relative or absolute insulin excess and impaired physiological 
Type 1 diabetes

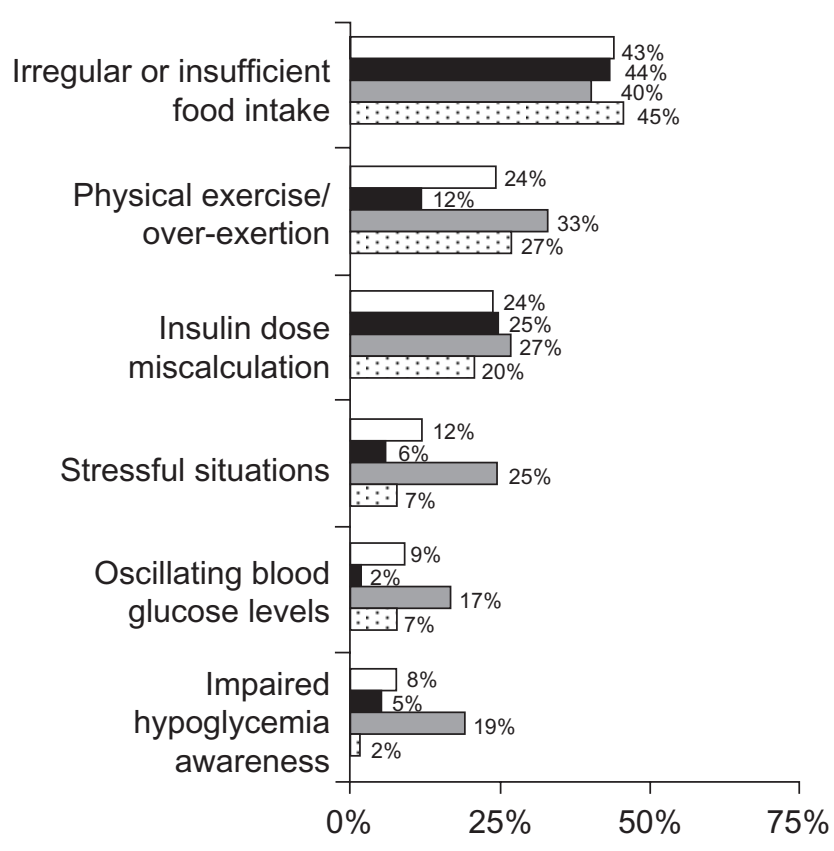

Type 2 diabetes

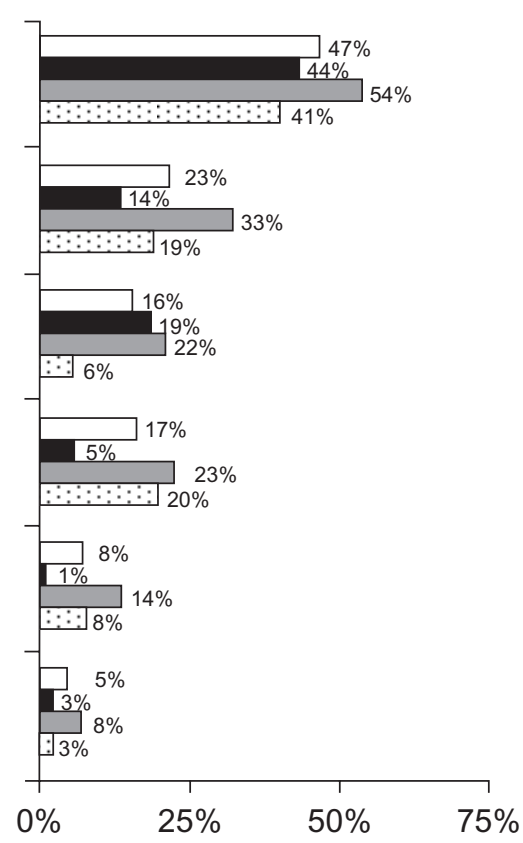

Figure 2 Causes identified by patients for severe hypoglycemic events (as \% of group). White bar = total of all countries (type I, 3।9; type 2, 320); black bar = UK (type I, I0I; type 2, I00), grey bar = Germany (type I, 94; type 2, I20), dotted bar = Spain (type I, I24; type 2, 100).

Reprinted from J Med Econ, I2, M Lammert, M Hammer, BM Frier, Management of severe hypoglycaemia: cultural similarities, differences and resource consumption in three European countries, 269-280, copyright (2009), with permission from Informa Healthcare Communications.

defenses against the fall in plasma glucose. ${ }^{41}$ Glucose counterregulation, the physiological defense mechanism that prevents or restores balance in the event of hypoglycemia, is impaired in patients with type 1 diabetes and those with advanced type 2 diabetes. Thus, compromised glucose counter-regulatory responses to hypoglycemia in the presence of an endogenous insulin-deficient state will manifest as a failure to decrease insulin levels and to increase glucagon levels accompanied by the attenuation of increased epinephrine levels. The blunting

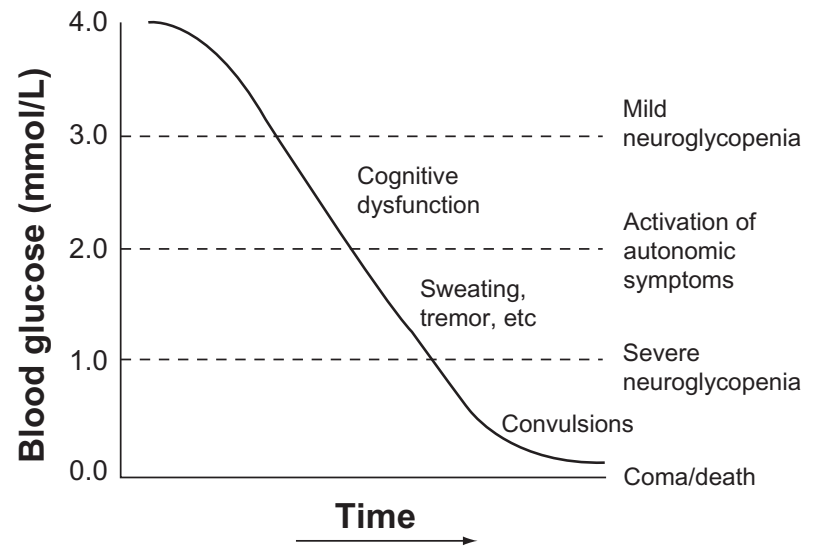

Figure 3 Glycemic threshold levels for onset of acute hypoglycemia symptoms in nondiabetic subjects.

Reprinted from Hypoglycaemia and diabetes, Handbook of Diabetes, Oxford: Blackwell Publishing Ltd, Ist revision, G Williams, JC Pickup (editors), copyright (1998), with permission from John Wiley \& Sons. of autonomic (adrenomedullary and sympathetic neural) response is attributed to the observed clinical presentation of hypoglycemia unawareness. Furthermore, it is postulated that the reduced sympathoadrenal response (the concept of hypoglycemia-associated autonomic failure) is induced by recent antecedent hypoglycemia, resulting in defective glucose counter-regulation and hypoglycemia unawareness that presents as recurrent cycles of hypoglycemia. ${ }^{9}$

\section{Burden of hypoglycemia Patient}

The adverse consequences of hypoglycemia cannot be underestimated. Untreated hypoglycemia can eventually lead to unconsciousness and seizures, which can prove fatal (Figure 3) ${ }^{37}$ If blood glucose levels are not quickly restored, continuing hypoglycemia can lead to a decline in brain glucose levels, which manifests as neuroglycopenic symptoms (Figure 3). ${ }^{36,38}$ There is evidence to suggest that hypoglycemia events in children have deleterious effects on cognitive functioning, with successive events resulting in permanent neurological changes in young children. ${ }^{8}$ Nocturnal hypoglycemia occurs in approximately $50 \%$ of children with diabetes, especially those aged below 7 years. ${ }^{42-44}$ Nocturnal hypoglycemia has been attributed to sudden nocturnal deaths (known as "dead in bed" syndrome), 
which account for $5 \%-6 \%$ of all deaths among young people with type 1 diabetes. ${ }^{8,45}$ Contributory factors leading to nocturnal hypoglycemia may include the fact that early warning symptoms are more difficult to detect when asleep, the longer time intervals between meals resulting in low blood glucose levels, or impaired counter-regulatory mechanisms. ${ }^{46}$

Hypoglycemia symptoms are distressing and impair the daily functioning of people with diabetes. ${ }^{47}$ They can lead to sufferers feeling tired, tense and ill at ease ${ }^{48,49}$ and affect their quality of life..$^{50}$ The Diabetes Attitudes, Wishes, and Needs (DAWN) study showed that $41 \%$ of people with diabetes $(n=5104)$ reported poor psychological well-being, with only $10 \%$ of patients reporting that they had received psychological treatment for their problems. ${ }^{51}$ Moreover, more health care professionals $(n=3287$; including primary care physicians, diabetes specialist physicians and nurses) felt able to identify and evaluate psychological needs (49\%-69\%) than had the resources to treat those needs $(38 \%-61 \%) .{ }^{51}$ Activities of daily living such as driving become too dangerous for the individual to perform and they may feel less able to partake in recreational and sporting activities, which may affect their quality of life. Elderly people with diabetes may also suffer fractures from falls due to hypoglycemia. ${ }^{52}$ In addition, the fear of future severe hypoglycemia events also negatively influences self-management of diabetes and quality of glycemic control. ${ }^{14,53,54}$

\section{Society}

The consequences and treatment of hypoglycemia impose a significant strain on health care systems and on society in general. ${ }^{28} \mathrm{~A}$ recent economic analysis of the direct (health care resource use including the cost of follow-up training after an event) and indirect (work productivity) costs of severe hypoglycemia in 639 patients from Germany, UK, and Spain showed that the average treatment costs incurred due to severe hypoglycemia were high ( $€ 533$ to $€ 691$ per person with type 2 diabetes and $€ 236$ to $€ 577$ per person with type 1 diabetes) and contributed significantly to the overall health care costs of diabetes in all three countries (Table 2). For nonhospitalized patients, telephone calls, visits to the doctor, blood glucose monitoring and patient education contributed significantly to health care costs. ${ }^{55}$ In the UK, the annual cost of acute treatment of hypoglycemia episodes (hospitalization and ambulances) was estimated at $£ 15$ million. ${ }^{56}$ Likewise, treatment of hypoglycemia episodes in type 2 diabetes patients in Sweden amounts to $€ 4.25$ million per year, with hospitalized treatment costing approximately 10 times more than those treated in the community. ${ }^{57}$
Table 2 Costs associated with severe hypoglycemia in three European countries (based on 2007 prices)

\begin{tabular}{|c|c|c|c|}
\hline & $\begin{array}{l}\text { Germany } \\
(€)\end{array}$ & $\begin{array}{l}\text { Spain } \\
(€)\end{array}$ & $\begin{array}{l}\text { UK } \\
\text { (UKE) }\end{array}$ \\
\hline \multicolumn{4}{|l|}{ HCP consultations } \\
\hline PCP office visit & 7.40 & 15.10 & 32.42 \\
\hline PCP phone call & 7.40 & 10.11 & 28.23 \\
\hline Diabetes specialist & 19.40 & 52.35 & 112.93 \\
\hline \multicolumn{4}{|l|}{ Emergency HCP access costs } \\
\hline Ambulance & 281.74 & 330.91 & 187.17 \\
\hline Emergency physician & 318.86 & 65.52 & 72.15 \\
\hline Taxi transfer & 21.48 & 10.55 & 10.00 \\
\hline Private car transfer & 4.10 & 5.00 & 2.60 \\
\hline Emergency call (treatment guidance) & 7.40 & $\mathrm{n} / \mathrm{a}$ & 10.46 \\
\hline Hotline call (emergency) & 7.40 & $\mathrm{n} / \mathrm{a}$ & 10.46 \\
\hline \multicolumn{4}{|l|}{ Hospital costs } \\
\hline Emergency room & $|40.6|$ & 786.91 & 73.00 \\
\hline Intensive care unit & $\mathrm{n} / \mathrm{a}$ & $|264.6|$ & 1657.37 \\
\hline General ward & $\mathrm{n} / \mathrm{a}$ & 405.90 & 502.96 \\
\hline Hospitalization tariff & 2517.00 & $\mathrm{n} / \mathrm{a}$ & 612.76 \\
\hline \multicolumn{4}{|l|}{ Treatments } \\
\hline Sugar (estimate) & 0.09 & 0.05 & 0.01 \\
\hline Sweet drinks (estimate) & 0.50 & 0.45 & 0.35 \\
\hline Sweets, chocolate (estimate) & 0.50 & 0.93 & 0.28 \\
\hline Oral glucose gel/paste & 0.75 & 5.85 & 3.65 \\
\hline Glucagon (im) & 27.74 & 21.40 & 11.52 \\
\hline Glucose (iv) & 27.74 & 1.86 & 2.55 \\
\hline \multicolumn{4}{|l|}{ Training and other costs } \\
\hline Education & 7.40 & 29.66 & 32.42 \\
\hline Dietary counseling & 7.40 & 29.66 & 32.42 \\
\hline Hypoglycemia awareness training & 7.40 & 29.66 & 32.42 \\
\hline Psychological counseling & 7.40 & 29.66 & 32.42 \\
\hline Leaflets, books & 2.21 & 2.21 & 1.50 \\
\hline Blood glucose test (patient self-test) & 0.50 & 0.89 & 0.29 \\
\hline Salary per hour & 20.74 & 10.67 & 11.92 \\
\hline
\end{tabular}

Adapted from J Med Econ, 12, M Hammer, M Lammert, SM Mejias, et al, Costs of managing severe hypoglycaemia in three European countries, 28I-290, copyright (2009), with permission from Informa Healthcare Communications.

Abbreviations: HCP, health care professional; PCP, primary care physician; n/a, not applicable; im, intramuscular; iv, intravenous.

\section{Prevention strategies}

The overall incidence of episodes and the likelihood of suffering from a severe episode can be reduced with effective education directed not only at the individual with diabetes, but at the parents, spouse or caregiver. In fact, the requirement for hypoglycemia education among friends, family and neighbors of patients emerged as a key theme in a recent focus group study that was conducted to elucidate information needs that would facilitate future improvements in the targeting of education on hypoglycemia. ${ }^{58}$ As advocated and provided by professional diabetes organizations, such education should include information on the main causes of hypoglycemia and on the self-management of diabetes (including how to recognize and act on early symptoms). ${ }^{59}$ Acknowledging the fact that young children and their families may not be 
as accurate at recognizing the early signs and symptoms of low blood glucose as adult patients with diabetes, the 2009 consensus guidelines developed by ISPAD explicitly stated that families of children and adolescents with diabetes should receive education regarding the situations when hypoglycemia was more likely to occur (in order to initiate more frequent blood glucose monitoring), including: when the treatment regimen is altered; in younger children; with lower HbA1c levels; during periods of frequent low blood glucose levels; when awareness of autonomic symptoms is reduced; during sleep; or after taking alcohol. ${ }^{8}$

One educational aspect of particular importance is the recommendation that individuals have an immediate source of glucose (for mild or moderate hypoglycemic episodes) and a glucagon kit (in the case of severe hypoglycemic episodes) always available. The American Diabetes Association provides simple "do/don't" guidance for those assisting patients who lose consciousness during a severe hypoglycemic event, which can be summarized as "DO NOT inject insulin, provide food or fluids, or put hands in their mouth; DO inject glucagon and call for emergency help". ${ }^{60}$ Moreover, as discussed in a later section, it is imperative that hypoglycemia education imparted to families or caregivers should encompass awareness and training on the use of the glucagon kit in a nonhospital setting. Importantly, carers of adolescents may experience distress and feel unable to adequately undertake the administration of glucagon in an emergency situation. These concerns and the dearth of literature examining glucagon administration formed the basis of an investigation on the techniques used to administer glucagon among 136 parents of teenagers and young children with diabetes. ${ }^{19}$ Among this study group, $82.8 \%$ of whom had received initial verbal education on glucagon administration by a diabetes educator, handling difficulties (69\% of parents) and inaccuracies in administering dosages were apparent and led the authors to conclude that training on glucagon administration requires "hands on" practice and follow-up assessment of skills.

General hypoglycemia education should also emphasize the importance of ensuring forward planning of meal timing and timing of insulin dosing if the individual is going to be driving, traveling or partaking in recreational activity. Insulin analogs are also increasingly being used to treat diabetes, and these have a lower risk of severe hypoglycemia than human insulins. ${ }^{61}$ In the context of educating patients on preventing hypoglycemia, the Diabetes Care and Education group of the American Dietetic Association propose a series of questions that individuals should pose to themselves to act as a prompt: "Can my diabetes medications cause hypoglycemia? Have my diabetes medications changed?"; "Has my meal plan changed? Am I eating regular meals and snacks?"; "Have I been more active than usual?"; "Did I drink alcoholic beverages on an empty stomach?". ${ }^{59}$ The need for hypoglycemia education is undisputed, but one retrospective cohort study suggests potential inadequacies remain with respect to education on the prevention of hypoglycemia. In this study, a review of patient charts for emergency department discharge instructions provided to patients hospitalized with possible hypoglycemia (64\% had confirmed hypoglycemia) revealed that such instructions rarely included recommendations to avoid recurrent hypoglycemia (3\% of cases), check blood glucose before driving $(0.4 \%)$, or to obtain glucagon emergency kits $(2 \%){ }^{62}$

Dissemination of relevant information to patients regarding diabetes self-management and hypoglycemia is increasingly undertaken in the form of various educational materials or media including videos, brochures, and structured teaching. Improvements in education on preventing hypoglycemia and how best to self-manage diabetes could ultimately reduce the pressure put on the emergency medical services. Indeed, interventional programs incorporating structured diabetes education (for example, implementation of a video and brochure or lessons [five 90-minute sessions for 5 weeks]) have achieved favorable outcomes in terms of reducing the incidence of severe hypoglycemia. ${ }^{63,64} \mathrm{~A}$ recent survey found that German and Spanish patients were much more likely to receive such training than those in the UK, which could explain why fewer patients in Germany experienced five or more episodes of severe hypoglycemia than those in Spain and the UK. ${ }^{28}$

\section{Management strategies}

Treatment of hypoglycemia is dependent on the duration and severity of the hypoglycemia episode. Mild-to-moderate hypoglycemia is easily self-treated with the oral intake of rapid-acting carbohydrates such as a glucose drink, tablets, or snacks. ${ }^{9}$ On the other hand, by virtue of its definition, severe hypoglycemia necessitates external help.

\section{Dextrose}

For patients who are unable to swallow oral glucose due to unconsciousness, seizures, or altered mental status, emergency personnel can administer a peripheral or central IV solution containing dextrose. Dextrose in water at a $50 \%$ concentration is the dose usually administered to adults, while a $25 \%$ concentration is usually administered to children. 
Dextrose $50 \%$ and $25 \%$ are heavily necrotic due to their hyperosmolarity properties, which can cause tissue necrosis if the IV line becomes infiltrated; ${ }^{65}$ therefore, they must only be administered via a patent IV line.

\section{Glucagon}

As the main counter-regulatory hormone to insulin, glucagon is the first-line treatment for severe hypoglycemia in insulin-treated patients with diabetes. Unlike dextrose, which must be administered intravenously by a qualified health care professional, glucagon can be administered by subcutaneous (SC) or intramuscular (IM) injection by trained parents or caregivers. This can prevent the delay in commencing treatment that is otherwise experienced while waiting for the arrival of emergency personnel, reducing the need for hospitalization and providing reassurance for patients and their caregivers. ${ }^{66}$ The hormone is secreted by the pancreas, and acts to maintain glucose production through glycogenolysis and gluconeogenesis in the liver. ${ }^{67}$ The pharmacokinetic and pharmacodynamic profiles of recombinant glucagon have been evaluated following SC and IM administration, with glucagon demonstrating a short halflife ( $~ 8-18$ minutes), and maximum plasma concentrations achieved a few minutes after SC or IM injection. ${ }^{68,69}$

\section{Efficacy, safety and tolerability}

Substantial evidence shows that glucagon is efficacious in restoring blood glucose levels and consciousness (Figure 4), and is safe and tolerable in treating severe hypoglycemia whether injected intravenously, intramuscularly, or subcutaneously. ${ }^{70-72}$ While parenteral glucagon is used to treat patients with type 1 diabetes experiencing a hypoglycemic episode, IV glucose is a commonly used treatment for severe hypoglycemia in type 2 diabetes. ${ }^{9}$ As glucagon stimulates insulin secretion in addition to glycogenolysis, ${ }^{9}$ use of glucagon in type 2 diabetes may be considered for those patients with advanced disease who are receiving intensive insulin therapy. ${ }^{27}$ Glucagon is not recommended for IV infusion or to be used in patients on sulfonylureas; ${ }^{9}$ for those patients, an IV glucose bolus followed by continuous IV infusion is preferred until the effects of the sulfonylureas have worn off. ${ }^{27}$ Nausea and vomiting are sometimes reported as side effects of glucagon particularly with doses $>1 \mathrm{mg}$, but such reports are rare and can occur after severe hypoglycemia even when glucagon is not used. The risks associated with glucagon use are lower than those associated with severe hypoglycemia, plus glucagon can lead to a faster recovery than calling for paramedics and waiting for them to start an

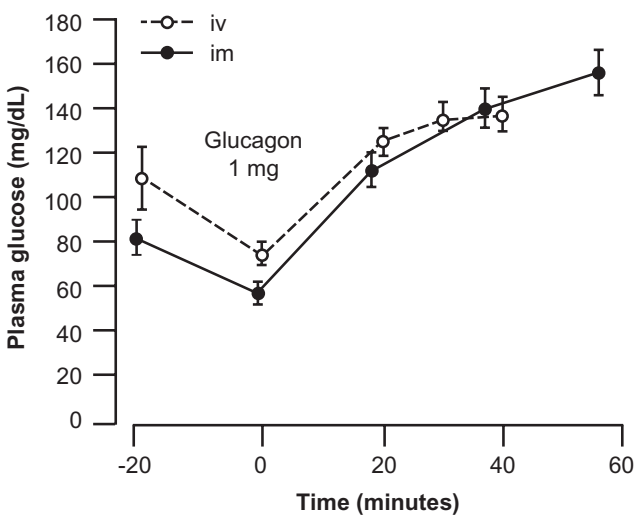

Figure 4 Changes in blood glucose levels before and after the administration of I mg biosynthetic glucagon.

Reprinted from Diabetes Res Clin Pract, 19, M Namba, T Hanafusa, N Kono, et al, Clinical evaluation of biosynthetic glucagon treatment for recovery from hypoglycemia developed in diabetic patients, 133-138, copyright (1993), with permission from Elsevier.

Abbreviations: iv, intravenous; im, intramuscular.

IV line to give dextrose. There have been reports of allergic reactions following glucagon administration, but these have usually been seen when treating indications other than hypoglycemia and there have been no reports of adverse reactions suggestive of glucagon toxicity. ${ }^{72}$

\section{Glucagon kits}

The Glucagon Emergency Kit (Eli Lilly and Co, Indianapolis, IN) and the GlucaGen ${ }^{\circledR}$ Hypokit $^{\circledR}$ (Novo Nordisk A/S, Bagsværd, Denmark) are the currently available glucagon kits administered by IM or SC injection. The glucagon kits comprise a brightly colored case, containing a vial of glucagon powder, a syringe prefilled with solvent, and text and graphic instructions for reconstitution and use, designed so that they are easy to locate and use in an emergency situation.

A $1 \mathrm{mg}$ dose of glucagon (reconstituted in $1 \mathrm{~mL}$ of sterile water) is recommended for adults and children over $25 \mathrm{~kg}$ in weight or children aged 6 to 8 years or above and a half dose $(0.5 \mathrm{~mL})$ is recommended for children below $25 \mathrm{~kg}$ in weight or younger than 6 to 8 years of age. To administer the kit, the user is instructed to open the vial by breaking off the plastic cap, to inject the solvent into the vial containing the glucagon powder, and to shake the vial until the reconstituted solution is clear and has no particles. They are then instructed to withdraw the reconstituted solution back into the syringe and to inject into the unconscious person's leg or abdomen immediately. The unconscious person should be rolled onto their side in case of vomiting during recovery. If the patient does not respond immediately after receiving glucagon, medical help should be sought and IV glucose administered as soon as possible. ${ }^{5,9}$ If the patient does respond 
to glucagon by regaining consciousness, it is advised that they are assessed in an emergency room due to depletion of their glycogen stores, which may lead to rebound hypoglycemia. ${ }^{27}$ For more information on the Glucagon Emergency Kit and the GlucaGen ${ }^{\circledR}$ Hypokit $^{\circledR}$, see http://www.humalog. com/humalog-diabetes-and-insulin/glucagon-tutorial.jsp and http://www.novonordisk.com/diabetes/public/hypokit/ hypokit/product-information.asp, respectively.

Continuous education on the use of glucagon kits is highly recommended for caregivers who should always be aware of the location of the kit, should store the kit at room temperature, and should always ensure that the expiration date has not passed. ${ }^{19}$ Training for family, caregivers and friends on how to use glucagon kits is vital to ensure accurate administration of glucagon ${ }^{19}$ and to reassure them that they cannot injure the patient by administering glucagon. It may be of benefit for family and caregivers to practice giving the injections with saline so that they are more confident if a real emergency happens. They should also be advised on the importance of avoiding any delay in treating the patient so that blood glucose levels can be raised as soon as possible.

\section{Conclusion}

Glucagon is a safe and reliable alternative to IV glucose infusion $^{70}$ and is the only treatment for severe hypoglycemia events that can be used in nonhospital environments. However, to date, glucagon remains underappreciated and underused ${ }^{19}$ despite its documented benefits. Underutilization of glucagon may partly be attributed to a lack of adequate education and training or may be a result of unsubstantiated fears of harming the patient or of the side effects. ${ }^{19}$ The same misconceptions are seen in schools, clubs and other childcare facilities leading to a further reluctance to inject glucagon. This situation is unfortunate because it means that the incidence of severe hypoglycemia will probably rise due to the increasing number of people with diabetes and the shift to more intensive insulin regimens. ${ }^{27}$

So how can management of severe hypoglycemia be improved? With the cooperation of patients, families, and health care providers, better information and continued education and more frequent use of glucagon, it may be possible to achieve short-term benefits in managing hypoglycemia episodes, long-term improvements in glycemic control, as well as reduced incidence of late diabetes complications, and fewer hospital admissions in diabetes patients. ${ }^{27}$ The introduction of training on the use of glucagon kits for school nurses, sports coaches and others who work with children would be worthwhile as it may lead to the same benefits.
The use of glucagon also has the potential to confer economic advantages and to free up health care resources by reducing the number of patients who have to be admitted to hospital with severe hypoglycemia. More importantly, glucagon treatment can ease the anxiety and worry that accompanies a severe hypoglycemia event. Since glucagon kits are easy to use and show minimal risk in terms of the effect of the drug on the patient and the procedure of injecting, there is a strong argument for more frequent use of these kits in the treatment of severe hypoglycemia.

\section{Acknowledgments/disclosure}

This paper was funded by Novo Nordisk A/S (Bagsværd, Denmark). Editorial assistance was provided by ESP Bioscience (Crowthorne, UK).

\section{References}

1. Diabetes Control and Complications Trial (DCCT) Resarch Group. The absence of a glycemic threshold for the development of longterm complications: the perspective of the Diabetes Control and Complications Trial. Diabetes. 1996;45(10):1289-1298.

2. The Diabetes Control and Complications Trial (DCCT) Research Group. Hypoglycemia in the Diabetes Control and Complications Trial. Diabetes. 1997;46(2):271-286.

3. UK Prospective Diabetes Study (UKPDS) Group. Intensive bloodglucose control with sulphonylureas or insulin compared with conventional treatment and risk of complications in patients with type 2 diabetes (UKPDS 33). Lancet. 1998;352(9131):837-853.

4. Skyler JS, Bergenstal R, Bonow RO, et al. Intensive glycemic control and the prevention of cardiovascular events: implications of the ACCORD, ADVANCE, and VA diabetes trials: a position statement of the American Diabetes Association and a scientific statement of the American College of Cardiology Foundation and the American Heart Association. Diabetes Care. 2009;32(1):187-192.

5. Stratton IM, Adler AI, Neil HA, et al. Association of glycemia with macrovascular and microvascular complications of type 2 diabetes (UKPDS 35): prospective observational study. Br Med J. 2000; 321(7258):405-412.

6. Wang PH, Lau J, Chalmers TC. Meta-analysis of effects of intensive blood-glucose control on late complications of type I diabetes. Lancet. 1993;341(8856):1306-1309.

7. Amiel SA, Dixon T, Mann R, Jameson K. Hypoglycaemia in type 2 diabetes. Diabet Med. 2008;25(3):245-254.

8. Clarke W, Jones T, Rewers A, Dunger D, Klingensmith GJ. Assessment and management of hypoglycemia in children and adolescents with diabetes. Pediatr Diabetes. 2009;10(Suppl 12):134-145.

9. Cryer PE, Davis SN, Shamoon H. Hypoglycemia in diabetes. Diabetes Care. 2003;26(6):1902-1912.

10. Cryer PE. Hierarchy of physiological responses to hypoglycemia: relevance to clinical hypoglycemia in type I (insulin dependent) diabetes mellitus. Horm Metab Res. 1997;29(3):92-96.

11. Laing SP, Swerdlow AJ, Slater SD, et al. The British Diabetic Association Cohort Study, II: cause-specific mortality in patients with insulin-treated diabetes mellitus. Diabet Med. 1999;16(6): 466-471.

12. Campbell IW. Metformin and the sulphonylureas: the comparative risk. Horm Metab Res Suppl. 1985;15:105-111.

13. Action to Control Cardiovascular Risk in Diabetes (ACCORD) Study Group. Long-term effects of intensive glucose lowering on cardiovascular outcomes. N Engl J Med. 2011;364(9):818-828. 
14. Wild D, von Maltzahn R, Brohan E, Christensen T, Clauson P, Gonder-Frederick L. A critical review of the literature on fear of hypoglycemia in diabetes: implications for diabetes management and patient education. Patient Educ Couns. 2007;68(1):10-15.

15. Lagarde WH, Barrows FP, Davenport ML, Kang M, Guess HA, Calikoglu AS. Continuous subcutaneous glucose monitoring in children with type 1 diabetes mellitus: a single-blind, randomized, controlled trial. Pediatr Diabetes. 2006;7(3):159-164.

16. Nathan DM, Buse JB, Davidson MB, et al; European Association for Study of Diabetes. Medical management of hyperglycemia in type 2 diabetes: a consensus algorithm for the initiation and adjustment of therapy: a consensus statement of the American Diabetes Association and the European Association for the Study of Diabetes. Diabetes Care. 2009;32:193-203.

17. Diabetes Research in Children Network (DirecNet) Study Group. The accuracy of the CGMS in children with type 1 diabetes: results of the diabetes research in children network (DirecNet) accuracy study. Diabetes Technol Ther. 2003;5(5):781-789.

18. Kovatchev B, Anderson S, Heinemann L, Clarke W. Comparison of the numerical and clinical accuracy of four continuous glucose monitors. Diabetes Care. 2008;31(6):1160-1164.

19. Harris G, Diment A, Sulway M, Wilkinson M. Glucagon administration - underevaluated and undertaught. Pract Diabetes Int. 2001;18(1):22-25.

20. Zammitt NN, Frier BM. Hypoglycemia in type 2 diabetes: pathophysiology, frequency, and effects of different treatment modalities. Diabetes Care. 2005;28(12):2948-2961.

21. Strachan MWJ. Frequency, causes, and risk factors for hypoglycemia in type 1 diabetes. In: Frier BM, Fisher BM, editors. Hypoglycemia in clinical diabetes. Chichester, UK: John Wiley; 2007:49-81.

22. Clarke W, Jones T, Rewers A, Dunger D, Klingensmith GJ. Assessment and management of hypoglycemia in children and adolescents with diabetes. Pediatr Diabetes. 2008;9(2):165-174.

23. Leese GP, Wang J, Broomhall J, et al. Frequency of severe hypoglycemia requiring emergency treatment in type 1 and type 2 diabetes: a population-based study of health service resource use. Diabetes Care. 2003;26(4):1176-1180.

24. MacLeod KM, Hepburn DA, Frier BM. Frequency and morbidity of severe hypoglycemia in insulin-treated diabetic patients. Diabet Med. 1993;10(3):238-245.

25. Reichard P, Berglund B, Britz A, Cars I, Nilsson BY, Rosenqvist U. Intensified conventional insulin treatment retards the microvascular complications of insulin-dependent diabetes mellitus (IDDM): the Stockholm Diabetes Intervention Study (SDIS) after 5 years. J Intern Med. 1991;230(2):101-108.

26. Gama R, Teale JD, Marks V. Best practice No 173: clinical and laboratory investigation of adult spontaneous hypoglycaemia. J Clin Pathol. 2003;56(9):641-646.

27. Pearson T. Glucagon as a treatment of severe hypoglycemia: safe and efficacious but underutilized. Diabetes Educ. 2008;34(1):128-134.

28. Lammert M, Hammer M, Frier BM. Management of severe hypoglycemia: cultural similarities, differences and resource consumption in three European countries. J Med Econ. 2009;12(4):269-280.

29. Clarke WL, Cox DJ, Gonder-Frederick LA, Julian D, Schlundt D, Polonsky W. Reduced awareness of hypoglycemia in adults with IDDM. A prospective study of hypoglycemic frequency and associated symptoms. Diabetes Care. 1995;18(4):517-522.

30. Gold AE, MacLeod KM, Frier BM. Frequency of severe hypoglycemia in patients with type I diabetes with impaired awareness of hypoglycemia Diabetes Care. 1994;17(7):697-703.

31. Hepburn DA, Patrick AW, Eadington DW, Ewing DJ, Frier BM. Unawareness of hypoglycemia in insulin-treated diabetic patients: prevalence and relationship to autonomic neuropathy. Diabet Med. 1990;7(8):711-717.

32. Henderson JN, Allen KV, Deary IJ, Frier BM. Hypoglycemia in insulintreated type 2 diabetes: frequency, symptoms and impaired awareness. Diabet Med. 2003;20(12):1016-1021.
33. Hepburn DA, Patrick AW, Brash HM, Thomson I, Frier BM. Hypoglycemia unawareness in type 1 diabetes: a lower plasma glucose is required to stimulate sympatho-adrenal activation. Diabet Med. 1991; 8(10):934-945.

34. Bulsara MK, Holman CD, Davis EA, Jones TW. The impact of a decade of changing treatment on rates of severe hypoglycemia in a population-based cohort of children with type 1 diabetes. Diabetes Care. 2004;27(10):2293-2298.

35. Pedersen-Bjergaard U, Agerholm-Larsen B, Pramming S, Hougaard P, Thorsteinsson B. Activity of angiotensin-converting enzyme and risk of severe hypoglycemia in type 1 diabetes mellitus. Lancet. 2001;357(9264):1248-1253.

36. Fanelli C, Pampanelli S, Epifano L, Rambotti AM, Ciofetta M, Modarelli F, et al. Relative roles of insulin and hypoglycemia on induction of neuroendocrine responses to, symptoms of, and deterioration of cognitive function in hypoglycemia in male and female humans. Diabetologia. 1994;37(8):797-807.

37. Boyle PJ, Schwartz NS, Shah SD, Clutter WE, Cryer PE. Plasma glucose concentrations at the onset of hypoglycemic symptoms in patients with poorly controlled diabetes and in nondiabetics. $N$ Engl J Med. 1988;318(23):1487-1492.

38. Deary IJ, Hepburn DA, MacLeod KM, Frier BM. Partitioning the symptoms of hypoglycemia using multi-sample confirmatory factor analysis. Diabetologia. 1993;36(8):771-777.

39. McAulay V, Deary IJ, Frier BM. Symptoms of hypoglycemia in people with diabetes. Diabet Med. 2001;18(9):690-705.

40. Gonder-Frederick L, Zrebiec J, Bauchowitz A, et al. Detection of hypoglycemia by children with type 1 diabetes 6 to 11 years of age and their parents: a field study. Pediatrics. 2008;121(3):e489-e495.

41. Cryer P. Hypoglycemia: Pathophysiology, Diagnosis and Treatment. New York: Oxford University Press; 1997.

42. Beregszaszi M, Tubiana-Rufi N, Benali K, Noel M, Bloch J, Czernichow P. Nocturnal hypoglycemia in children and adolescents with insulindependent diabetes mellitus: prevalence and risk factors. $J$ Pediatr. 1997;131(1 Pt 1):27-33.

43. Lopez MJ, Oyarzabal M, Barrio R, et al. Nocturnal hypoglycemia in IDDM patients younger than 18 years. Diabet Med. 1997;14(9): 772-777.

44. Porter PA, Keating B, Byrne G, Jones TW. Incidence and predictive criteria of nocturnal hypoglycemia in young children with insulindependent diabetes mellitus. J Pediatr. 1997;130(3):366-372.

45. Koltin D, Daneman D. Dead-in-bed syndrome - a diabetes nightmare. Pediatr Diabetes. 2008;9(5):504-507.

46. Banarer S, Cryer PE. Sleep-related hypoglycemia-associated autonomic failure in type 1 diabetes: reduced awakening from sleep during hypoglycemia. Diabetes. 2003;52(5):1195-1203.

47. Wredling R, Levander S, Adamson U, Lins PE. Permanent neuropsychological impairment after recurrent episodes of severe hypoglycemia in man. Diabetologia. 1990;33(3):152-157.

48. Gold AE, MacLeod KM, Frier BM, Deary IJ. Changes in mood during acute hypoglycemia in healthy participants. J Pers Soc Psychol. 1995; 68(3):498-504.

49. McCrimmon RJ, Frier BM, Deary IJ. Appraisal of mood and personality during hypoglycemia in human subjects. Physiol Behav. 1999;67(1): 27-33.

50. Zhang Y, Wieffer H, Modha R, Balar B, Pollack M, Krishnarajah G. The burden of hypoglycemia in type 2 diabetes: a systematic review of patient and economic perspectives. J Clin Outcomes Manage. 2010;17(12):547-557.

51. Peyrot M, Rubin RR, Lauritzen T, Snoek FJ, Matthews DR, Skovlund SE. Psychosocial problems and barriers to improved diabetes management: results of the Cross-National Diabetes Attitudes, Wishes and Needs (DAWN) Study. Diabet Med. 2005;22(10): 1379-1385

52. Frier BM. Living with hypoglycemia. In: Frier BM, Fisher BM, editors. Hypoglycemia in clinical diabetes. Chichester, UK: John-Wiley; 2007:309-332. 
53. Banck-Petersen P, Larsen T, Perdersen-Bjergaard U, Bie-Olsen L, Høi-Hansen T, Thorsteinsson B. Concerns about hypoglycemia and late complications in patients with insulin-treated diabetes. Eur Diabetes Nursing. 2007;4(3):113-118.

54. Currie CJ, Morgan CL, Poole CD, Sharplin P, Lammert M, McEwan P. Multivariate models of health-related utility and the fear of hypoglycemia in people with diabetes. Curr Med Res Opin. 2006;22(8):1523-1534.

55. Hammer M, Lammert M, Mejias SM, Kern W, Frier BM. Costs of managing severe hypoglycemia in three European countries. $\mathrm{J} \mathrm{Med}$ Econ. 2009;12(4):281-290.

56. Department of Health, UK (2008). Transplant hope for diabetes patients. Press release. London, UK; February 11, 2008.

57. Jonsson L, Bolinder B, Lundkvist J. Cost of hypoglycemia in patients with Type 2 diabetes in Sweden. Value Health. 2006;9(3):193-198.

58. Sutton L, Chapman-Novakofski K. Hypoglycemia education needs. Qual Health Res. March 10, 2011. [Epub ahead of print].

59. Diabetes Care and Education Dietetic Practice Group of the American Dietetic Association. Patient Education Handout. Managing and Preventing Hypoglycemia. 2008. Available at: http://www.dce.org/ pub_publications/education.asp. Accessed April 1, 2011.

60. American Diabetes Association. Available at: http://www.diabetes. org/living-with-diabetes/treatment-and-care/blood-glucose-control/ hypoglycemia-low-blood.html. Accessed April 1, 2011.

61. Bartley PC, Bogoev M, Larsen J, Philotheou A. Long-term efficacy and safety of insulin detemir compared to Neutral Protamine Hagedorn insulin in patients with Type 1 diabetes using a treat-to-target basalbolus regimen with insulin aspart at meals: a 2-year, randomized, controlled trial. Diabet Med. 2008;25(4):442-449.

62. Ginde AA, Pallin DJ, Camargo CA Jr. Hospitalization and discharge education of emergency department patients with hypoglycemia. Diabetes Educ. 2008;34(4):683-691.

63. Hermanns N, Kulzer B, Krichbaum M, Kubiak T, Haak T. Long-term effect of an education program (HyPOS) on the incidence of severe hypoglycemia in patients with type 1 diabetes. Diabetes Care. 2010; 33(3):e36.
64. Nordfeldt S, Johansson C, Carlsson E, Hammersjo J. Persistent effects of a pedagogical device targeted at prevention of severe hypoglycemia: a randomized, controlled study. Acta Paediatr. 2005; 94(10):1395-1401.

65. Kumar RJ, Pegg SP, Kimble RM. Management of extravasation injuries. ANZ J Surg. 2001;71(5):285-289.

66. Children with Diabetes. Robin - the importance of having a glucagon emergency kit on hand at all times. 2005 [last updated 16 March 2005]. Available at: www.childrenwithdiabetes.com/parents/d_03_160.htm. Accessed December 1, 2010.

67. Fonjallaz P, Loumaye E. Glucagon rDNA origin (GlucaGen) and recombinant LH. (no. 12 in a series of articles to promote a better understanding of the use of genetic engineering). J Biotechnol. 2000;79(2): 185-189.

68. Graf CJ, Woodworth JR, Seger ME, Holcombe JH, Bowsher RR, Lynch R. Pharmacokinetic and glucodynamic comparisons of recombinant and animal-source glucagon after IV, IM, and SC injection in healthy volunteers. J Pharm Sci. 1999;88(10):991-995.

69. GlucaGen HypoKit [prescribing information]. Novo Nordisk, A/S. Denmark, 2008.

70. Carstens S, Sprehn M. Prehospital treatment of severe hypoglycemia: a comparison of intramuscular glucagon and intravenous glucose. Prehosp Disaster Med. 1998;13(2-4):44-50.

71. Namba M, Hanafusa T, Kono N, Tarui S. Clinical evaluation of biosynthetic glucagon treatment for recovery from hypoglycemia developed in diabetic patients. The GL-G Hypoglycemia Study Group. Diabetes Res Clin Pract. 1993;19(2):133-138.

72. Patrick AW, Collier A, Hepburn DA, Steedman DJ, Clarke BF, Robertson C. Comparison of intramuscular glucagon and intravenous dextrose in the treatment of hypoglycemic coma in an accident and emergency department. Arch Emerg Med. 1990;7(2):73-77.

\section{Publish your work in this journal}

Diabetes, Metabolic Syndrome and Obesity: Targets and Therapy is an international, peer-reviewed open-access journal committed to the rapid publication of the latest laboratory and clinical findings in the fields of diabetes, metabolic syndrome and obesity research. Original research, review, case reports, hypothesis formation, expert opinion and commentaries are all considered for publication. The manuscript management system is completely online and includes a very quick and fair peer-review system, which is all easy to use. Visit http://www.dovepress.com/testimonials.php to read real quotes from published authors. 